\title{
A Diversity-Oriented Strategy for the Construction of Tetrasubstituted Pyrroles via Coupled Domino Processes
}

\author{
David Tejedor, ${ }^{\dagger \ddagger}$ David González-Cruz, ${ }^{\dagger}$ Fernando García-Tellado, ${ }^{\dagger *}$ José Juan Marrero-Tellado $^{\S \ddagger}$ and \\ Matías López Rodríguez \\ Instituto de Productos Naturales y Agrobiología, Consejo Superior de Investigaciones Cientificas, Avda. Astrofisico \\ Francisco Sánchez 3, 38206 La Laguna, Tenerife, Canary Islands, Spain; Instituto Canario de Investigación del \\ Cáncer (www.icic.es) and Instituto Universitario de Bioorgánica Antonio González, Universidad de La Laguna, \\ Avda. Astrofísico Francisco Sánchez 2, 38206 La Laguna, Tenerife, Canary Islands, Spain
}

RECEIVED DATE (automatically inserted by publisher); fgarcia@ipna.csic.es

Domino processes have received great attention from the chemical community because they address fundamental principles of synthetic efficiency and reaction processing. ${ }^{1}$ Over the last four years, we have been involved in a research program aimed at developing metal-free and diversity oriented domino-based syntheses of biologically relevant heterocyclic scaffolds. ${ }^{2}$ Our design principle is based on the expected multiplicative effect on molecular complexity achieved by a chain of two or more coupled domino processes in the same reaction vessel. This approach requires a careful design of each of the participant domino processes. To be coupled in a chain manner, each domino process must generate a suitably functionalized molecule able to be simultaneously engaged in the subsequent complexity-generating domino process and so on. Additionally, the whole process would be performed in a format amenable for application in combinatorial chemistry. Experimentally, the transformation of this concept in a one synthetic step strategy is not a simple task due to the unattainable kinetic tuning of each of the numerous chemical reactions involved. A more feasible approach should consist in the transformation of this concept in a one-pot synthetic strategy. In this new scenario, the consecutive coupled domino processes should be performed one at a time and linked in a onepot operation. In a first experimental approach, we chose the simple model shown in eq 1, addressing the synthesis of polysubstituted pyrroles. The protocol combines two coupled domino processes: the trialkylamine-catalyzed synthesis of enolprotected propargylic alcohols $\mathbf{1}^{2}$ (domino I) and their sequential transformation into pyrroles $\mathbf{3}$ (domino II). The key for this transformation came from a serendipitously discovered spontaneous rearrangement of 1,3-oxazolidines 2 to pyrroles 3 .

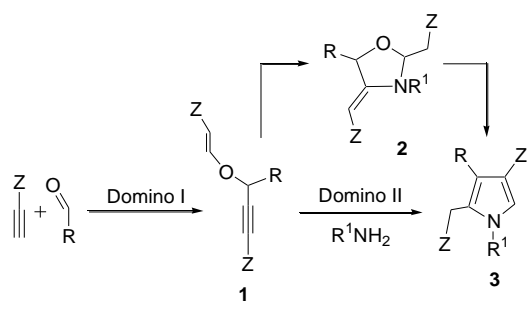

Polysubstituted pyrroles are common pharmacophores of numerous natural antibiotics and alkaloids ${ }^{3}$ and they have also found applications in the field of material chemistry. ${ }^{4}$ These properties are of considerable interest in the development of new efficient syntheses of these heterocycles. Among the plethora of methods available for pyrrole construction, ${ }^{3}$ metal-based strategies $^{5}$ and 1,3-dipolar cycloadditions ${ }^{6}$ have concentrated the most attention. In contrast, the number of examples reported in the literature dealing with metal-free, modular and direct syntheses of these heterocycles is scarce. ${ }^{7}$ Therefore, there is a clear demand for new metal-free, modular and direct synthetic protocols with atom-economy, easy reaction processing, general applicability and environmental care performance.

1,3-Oxazolidines $\mathbf{2}$ are readily obtained in a one-pot manner by the ytterbium-catalyzed reaction ${ }^{8}$ of the conjugated alkynoates 1 and primary amines (eq 2). Pure 1,3-oxazolidines 2 rearrange to

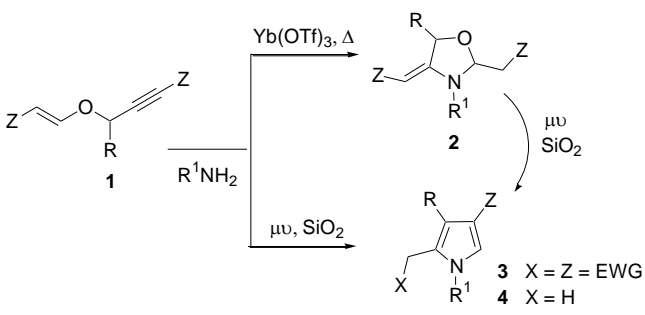

(2)

pyrroles 3 when they are stored on the bench without solvent (eq 2 ). This rearrangement is very slow at room temperature and needs months to be completed. ${ }^{9}$ While heating speeds up this process from months to hours (see supporting information for full details), microwave ( $\mu v)$-irradiation assists this rearrangement reducing the reaction time from hours to minutes. As an example, $\mu v$-irradiation $(900 \mathrm{~W})$ of a sample of $\mathbf{2} \mathbf{i}$ absorbed on silica gel (1g silica $\mathrm{gel} / \mathrm{mmol}$ ) (neat $\mathbf{2}$ are transparent to $\mu \mathrm{v}$-irradiation), for 5 minutes in a domestic $\mu v$-oven, cleanly afforded the 1,2,3,4tetrasubstituted pyrrole $3 \mathbf{i}$ in $78 \%$ yield with traces of the decarboxylated derivative 4 . This result proved to be general for all of the oxazolidines assayed. After some experimentation, we found that tetrasubstituted pyrroles $\mathbf{3}$ could be directly synthesized from scaffolds $\mathbf{1}$ and the primary amines by $\mu v-$ irradiation of a silica gel absorbed mixture of both components (eq 2, Table 1). Overall, this transformation constitutes a solventfree domino process involving a 1,3-oxazolidine synthesis and its subsequent skeletal rearrangement. The process is general for the amine (Entries 1-7) and tolerates a range of functionalities in the aldehyde (Entries 8-16). Even aniline, a bad nucleophile, transforms alkynoate 1a into oxazolidine $\mathbf{3 b}$ (Entry 2). $\alpha$ -

\footnotetext{
Consejo Superior de Investigaciones Científicas

* Instituto Canario de Investigación del Cáncer

$\S$ Universidad de La Laguna
} 
Oxygenated aldehydes afford conjugated alkynoates 1p and pyrroles 3p with moderate efficiency (Entry 16).

The complete synthetic protocol was performed by linking the two coupled domino processes involved (domino I and domino II) in a one-pot manner (Figure 1) (Table 1). Overall, these two linked and coupled domino processes build up two carboncarbon bonds, two carbon-nitrogen bonds and an aromatic ring in a regioselective and efficient manner. The overall yields range from 40 to $55 \%$ reflecting the high chemical efficiency of each of the reactions involved (at least 9 reactions, $>90 \%$ average yield). In addition, the reaction times are very short (less than $1 \mathrm{~h}$ ) and the processing is extremely bench- and environment-friendly (see supporting information).

Table 1. Synthesis of pyrroles 3 from conjugated alkynoates $\mathbf{1}$ $(\text { domino })^{\mathrm{a}}$ and from alkyl propiolate and aldehydes (one-pot) ${ }^{\mathrm{b}}$

\begin{tabular}{|c|c|c|c|c|c|c|}
\hline $\begin{array}{l}\text { En } \\
\text { try }\end{array}$ & $\mathbf{Z}$ & $\mathbf{R}$ & $\mathbf{R}^{1}$ & $1(\%)$ & $\begin{array}{l}\text { Domi- } \\
\text { no } \\
(\%)^{\mathrm{c}}\end{array}$ & $\begin{array}{l}\text { One } \\
\text {-pot } \\
(\%)^{\mathrm{c}}\end{array}$ \\
\hline 1 & $\mathrm{CO}_{2} \mathrm{Me}$ & $\mathrm{Et}$ & $\mathrm{Bn}$ & $1 \mathbf{a}(87)$ & 3a (74) & (44) \\
\hline 2 & $\mathrm{CO}_{2} \mathrm{Me}$ & Et & $\mathrm{Ph}$ & & $3 \mathbf{b}(38)^{\mathrm{d}}$ & \\
\hline 3 & $\mathrm{CO}_{2} \mathrm{Me}$ & Et & pOMe-Ph & & $3 \mathrm{c}(56)^{\mathrm{d}}$ & \\
\hline 4 & $\mathrm{CO}_{2} \mathrm{Et}$ & Et & pOMe-Ph & & $3 d^{d}$ & (53) \\
\hline 5 & $\mathrm{CO}_{2} \mathrm{Et}$ & Et & $\mathrm{Bn}$ & $\mathbf{1 e}(88)$ & 3e (77) & (51) \\
\hline 6 & $\mathrm{CO}_{2} \mathrm{Me}$ & $\mathrm{Et}$ & (S)PhCHMe & & $3 f(72)$ & (47) \\
\hline 7 & $\mathrm{CO}_{2} \mathrm{Me}$ & Et & Amino acid & & $3 \mathbf{g}(69)$ & (42) \\
\hline 8 & $\mathrm{CO}_{2} \mathrm{Et}$ & $\mathrm{Me}$ & $\mathrm{Bn}$ & $\mathbf{1 h}(73)$ & 3h (76) & \\
\hline 9 & $\mathrm{CO}_{2} \mathrm{Me}$ & Hex & $\mathrm{Bn}$ & $1 \mathrm{i}(76)$ & $3 \mathbf{i}(61)$ & \\
\hline 10 & $\mathrm{CO}_{2} \mathrm{Et}$ & Hex & $\mathrm{Bn}$ & & $3 \mathbf{j}$ & (47) \\
\hline 11 & $\mathrm{CO}_{2} \mathrm{Et}$ & 3-butenyl & $\mathrm{Bn}$ & $\mathbf{1 k}(79)$ & $\mathbf{3 k}(60)$ & (41) \\
\hline 12 & $\mathrm{CO}_{2} \mathrm{Et}$ & Cit. ${ }^{\mathrm{f}}$ & $\mathrm{Bn}$ & $11(68)$ & $31(65)$ & (49) \\
\hline 13 & $\mathrm{CO}_{2} \mathrm{Et}$ & $i \operatorname{Pr}$ & $\mathrm{Bn}$ & $1 \mathbf{m}(85)$ & $3 \mathbf{m}(63)$ & (46) \\
\hline 14 & $\mathrm{CO}_{2} \mathrm{Me}$ & $i \mathrm{Pr}$ & $\mathrm{Bn}$ & $1 \mathbf{n}(81)$ & 3n $(58)$ & \\
\hline 15 & $\mathrm{CO}_{2} \mathrm{Et}$ & $c \operatorname{Pr}$ & $\mathrm{Bn}$ & $10(72)$ & 3o(70) & (46) \\
\hline 16 & $\mathrm{CO}_{2} \mathrm{Et}$ & $\mathrm{BnOCH}_{2}$ & $\mathrm{Bn}$ & $\mathbf{1 p}(41)$ & $3 \mathbf{p}(55)$ & \\
\hline
\end{tabular}

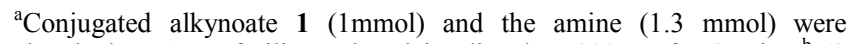
absorbed on $1 \mathrm{~g}$ of silica gel and irradiated at $900 \mathrm{~W}$ for $\left.8 \mathrm{~min} ;{ }^{\mathrm{b}} 1\right)$ Aldehyde $(1 \mathrm{mmol})$, alkyl propiolate $(2 \mathrm{mmol}), \mathrm{Et}_{3} \mathrm{~N}(0.5 \mathrm{mmol}), 0^{\circ} \mathrm{C}, 30$ min; 2) silica gel $(1 \mathrm{~g})$, amine $(1.3 \mathrm{mmol})$; 3) $\mu v$-irradiation $(900 \mathrm{~W}), 8$ min; ${ }^{\mathrm{c}}$ Yields of isolated pyrroles; ${ }^{\mathrm{d}} 2 \mathrm{~g}$ of silica gel were used; ${ }^{\mathrm{e}}$ Amino acid is ethyl 3-aminobutyrate; ${ }^{\mathrm{f}} \mathrm{Cit}$. from (S)-(-)citronellal.

Scheme 1. Proposed mechanism for the $\mu v$-assisted rearrangement of 1,3-oxazolidines 2 to pyrroles 3 .

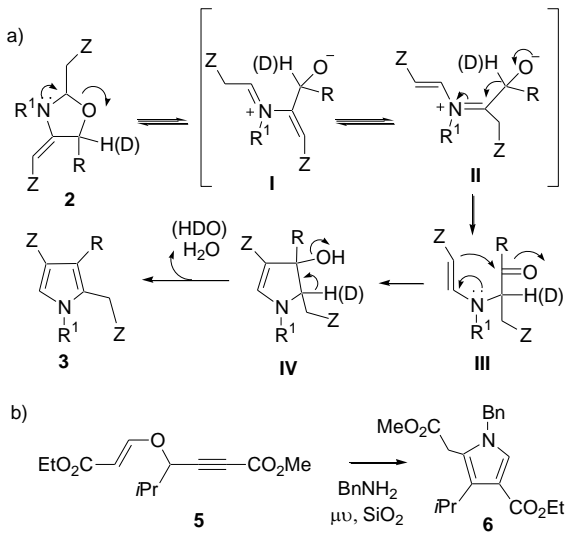

A plausible mechanism for this new $\mu v$-assisted rearrangement of 1,3-oxazolidines $\mathbf{2}$ is outlined in Scheme 1a. Two experimental features support this mechanism: 1) $\mathrm{d}_{4-}$ acetaldehyde produces the pyrrole $3 \mathbf{e}$ with deuterium at the methyl position but not in the ring; 2) conjugated alkynoate $\mathbf{5}$, with two different ester groups, produces pyrrole $\mathbf{6}$ as the only isomer (Scheme 1b).

Finally, selective hydrolysis of the aliphatic ester generates an additional point for functional diversity on the pyrrole molecule (see supporting information for full details).

In summary, we have developed a metal-free, modular and direct synthesis of 1,2,3,4-tetrasubstituted pyrroles from simple and commercially available components. The synthetic protocol embodies two coupled domino processes and is neatly accomplished in a one-pot manner according to the new chemical efficiency paradigm. ${ }^{10}$ We believe that this method will have a significant application in the fields of combinatorial chemistry, diversity oriented synthesis and drug research.

Acknowledgement. Dedicated to Professor Angel Gutierrez Ravelo on the occasion of his 62nd birthday. This research was supported by the Spanish MEC (PPQ2002 - 04361-C04 - 03). F.G.T. and D.T. thank the Instituto Canario de Investigación del Cáncer for financial support (ISCiii, RTICCC C03/10). D.G.C. thanks the Spanish MEC for a FPI grant. F.G.T. thanks Dr P. de Armas and Prof. V. S. Martín for helpful comments on this work

Supporting Information Available: Crystallographic data of $\mathbf{3 n}$ and experimental preparations for 1a-p, 3a-p, $\mathbf{5}$ and $\mathbf{6}$, This material is available free of charge via the Internet at htpp://pubs.acs.org.

References
(1) Tietze, L. F.; Haunert, F.in Stimulating Concepts in Chemistry,
Shibasaki, M., Stoddart, J. F., Vögtle, F., Eds.; Wiley-VCH: Weinheim, Germany 2000, p. 39-64.

(2) (a) Tejedor, D.; García-Tellado, F.; Marrero-Tellado, J. J.; de Armas, P. Chem.-Eur. J. 2003, 9, 3122-3131; (b) Tejedor, D.; López, G. V.; García-Tellado, F.; Marrero-Tellado, J. J.; de Armas, P.; Terrero, D. J. Org. Chem. 2003, 68, 3363-3365; (c) de Armas, P.; García-Tellado, F.; Marrero-Tellado, J. J.; Tejedor, D.; Maestro, M. A.; González-Platas, J. Org. Lett. 2001, 3, 1905-1908.

(3) Le Quesne, P. W.; Dong, Y.; Blythe, T. A. in Alkaloids: Chemical and biological perspectives, Pelletier S. W. Ed.; Pergamon, 1999, Vol. 13, p. 238; b) Jones, R. A. in Pyrroles, Part II, The Synthesis, Reactivity and Physical Properties of Substituted Pyrroles, Wiley: New York, 1992.

(4) Handbook of Conducting Polymers, $2^{\text {nd }}$ ed.; Skotheim, T. A., Elsenbaumer, R. L., Reynolds, J. R. Eds.; Marcel Decker: New York, 1998.

(5) For recent examples of metal-based one-pot synthesis: (a) Dhawan, R.; Arndtsen, B. A. J. Am. Chem. Soc. 2004, 126, 468-469; (b) Braun, R. U.; Zeitler, K.; Muller, T. J. J. Org. Lett. 2001, 3, $3297-$ 3300; for recent examples from preformed scaffolds: (c) Kim, J. T.; Kel' in, A. V.; Gevorgyan, V. Angew. Chem. Int. Ed. Engl. 2003, 42, 98-101; (d) Gabriele, B.; Salerno, G.; Fazio, A. J. Org. Chem. 2003, 68, 7853-7861; (e) Gabriele, B.; Dalerno, G.; Fazio, A.; Campana, F. B. Chem. Commun. 2002, 1408-1409; (f) Paulus, O.; Alcaraz, G.; Vaultier, M. Eur. J. Org. Chem. 2002, 2565-2572; (g) Kel'in, A. V.; Srmek, A. W.; Gevorgyan, V. J. Am. Chem. Soc. 2001, 123, 2074-2075; (h) Lee, C.; Yang, L.; Hwu, T.; Feng, A.; Tseng, V.; Luh, T. J. Am. Chem. Soc. 2000, 122, 4992-4993.

(6) Nair, V.; Rajesh, C.; Vinod, A. U.; Bindu, S.; Sreekanth, A. R.; Mathen, J. S.; Balagopal, L. Acc. Chem. Res. 2003, 36, 899-907.

(7) (a) Ranu, B. C.; Dey, S. S. Tetrahedron Lett. 2003, 44, 2865-2868; (b) Ranu, B. C.; Haijra, A.; Jana, U. Synlett, 2000, 75-76.

(8) Mastsubara, S.; Yoshioka, M.; Utimoto, K. Chem. Lett. 1994, 827830.

(9) Other spontaneous rearrangements: (a) Polyak, F.; Dorofeeva, T.; Zelchans, G.; Shustov, G. Tetrahedron Lett. 1996, 37, 8223-8226; (b) Sheradsky, T.; Silcoff, E. R. Journal of Heterocyclic Chemistry 1996, 33, 1271-1274; (c) Le Rouzic, A.; Duclos, M.; Patin, H. Bull. Soc. Chim. Fr. 1991, 952-961.

(10) Trost, B. M. Science 1991, 254, 1471-1477. 


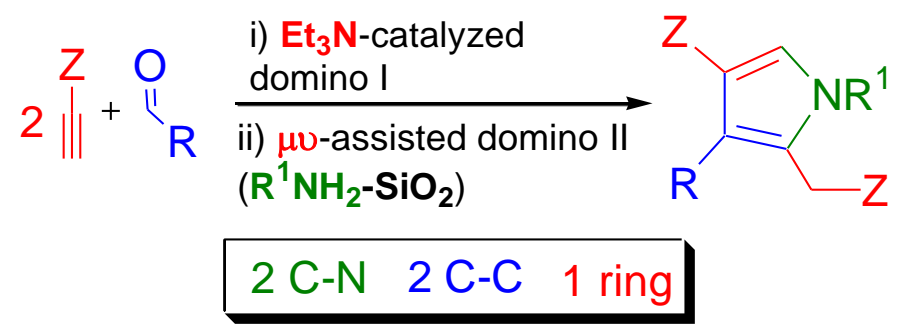

A new microwave-assisted rearrangement of 1,3-oxazolidines scaffolds is the basis for a new, metal-free, direct and modular construction of tetrasubstituted pyrroles from terminal conjugated alkynes, aldehydes and primary amines. This new reaction manifold entails two linked domino processes in a one-pot manner with both atom- and bond-efficiency and under very simple and environment-friendly experimental conditions. 